\title{
A Novel Inward Gradient Self-Lubrication Layer with Soft Alloys and Its Lubricating Mechanism
}

\author{
Songshan Yan, ${ }^{1}$ Ling Qin, ${ }^{2,3}$ Rui Hu, ${ }^{4}$ and Zuomin Liu ${ }^{1}$ \\ ${ }^{1}$ School of Mechanical and Electronic Engineering, Wuhan University of Technology, Wuhan 430070, China \\ ${ }^{2}$ School of Automotive Engineering, Wuhan University of Technology, Wuhan 430070, China \\ ${ }^{3}$ Hubei Key Laboratory of Advanced Technology for Automotive Components, Wuhan University of Technology, \\ Wuhan 430070, China \\ ${ }^{4}$ Jiangxi Province Key Laboratory of Precision Drive and Control, Nanchang Institute of Technology, Nanchang 330099, China \\ Correspondence should be addressed to Ling Qin; qinling@whut.edu.cn
}

Received 21 December 2015; Accepted 13 March 2016

Academic Editor: Patrice Berthod

Copyright (C) 2016 Songshan Yan et al. This is an open access article distributed under the Creative Commons Attribution License, which permits unrestricted use, distribution, and reproduction in any medium, provided the original work is properly cited.

A novel ceramic composite inward gradient distribution layer has been developed. The layer is a lubricating layer in which soft-metal lubricants are compounded into the ceramic matrix by high frequency induction infiltrating method. The design of the layer and its lubricating mechanism are investigated in the paper. The results show that the property of the layer greatly depends on the wetting angle of the soft-metal lubricants on the matrix and the proportion of $\mathrm{Ag}, \mathrm{Cu}, \mathrm{Sn}$, and $\mathrm{Pb}$ as well as the infiltrating parameters. Based on a lot of experiments, a novel inward gradient layer with Pb28Sn19Ag6Cu has been developed. The layer has an excellent lubricating property (friction coefficient about $0.2 \sim 0.3$ at $600^{\circ} \mathrm{C}$ ). The research reveals the lubricating mechanism, observing the phenomenon that the soft-metal in the matrix diffuses out of the frictional surface, and measures the lubricating film thickness as about $20 \mu \mathrm{m}$ on the worn surface.

\section{Introduction}

Self-lubricating coatings are widely introduced to solve wear and lubrication problems in extreme abrasion conditions [1-3]. However, the unsoundness of the bonding strength between coating and the substrate always puzzles the engineering fields and limits its application range, especially in extreme abrasion conditions. Therefore, besides lubricating properties of coating, studies on composite technology, novel lubrication theories, and preparation processes are laying increasing emphasis on solving the bonding strength problem $[4,5]$.

Recently, Liu and Wang have developed a kind of novel porous metal cermet with orderly micropores structure $[6,7]$. The interpenetrating network structure of the cermet allows lubricants, such as soft metal, to be infiltrated into the ceramic matrix and form an inward gradient lubricating layer, so that the tribological property of the ceramic composite can be greatly improved due to the combination of high strength at high temperature, wear resistance of the ceramic matrix, and self-lubricating characteristics. Particularly, Liu studied the diffusing mechanisms of the porous cermet infiltrating the single soft-metal and effect of some operating variables on its tribological properties [7]. However, when the soft alloys with different elements are mixed and infiltrated into the porous cermet at elevated temperature, a new material structure and some interesting lubricating phenomenon also existed. In fact, it can be observed that the orderly micropores structure of material can be used to develop a new inward gradient lubricating layer by design of the mixed soft alloys and infiltrated them into the porous cermet; a new inward gradient lubricating layer can be formed. In the paper, its design of infiltration agent and lubricating mechanisms are discussed.

\section{Experiments}

2.1. Preparation of Porous Matrix. To fabricate the metal ceramic matrix with orderly micropores structure, a mixture of $74.1 \mathrm{vol} . \% \mathrm{Fe}-\mathrm{Cr}-\mathrm{W}-\mathrm{Mo}-\mathrm{V}$ metal alloy powder and 


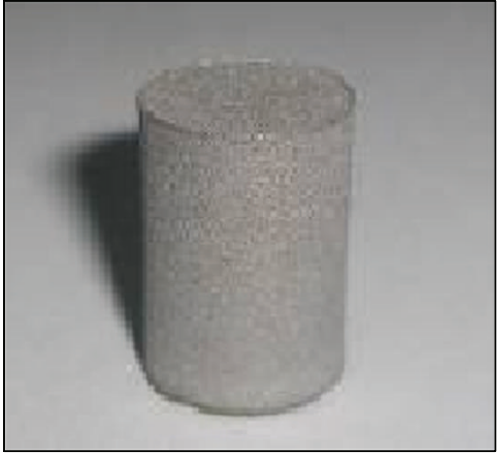

(a) Matrix specimen $(\phi 12 \times 17)$

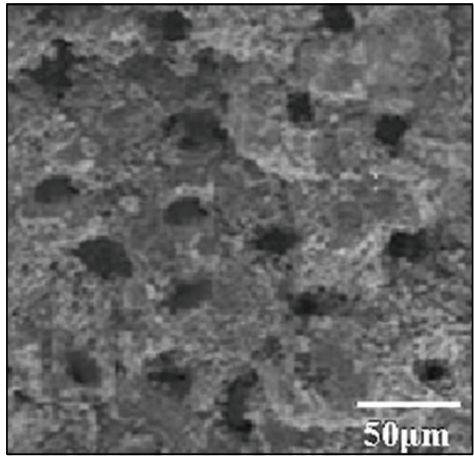

(b) Open pores

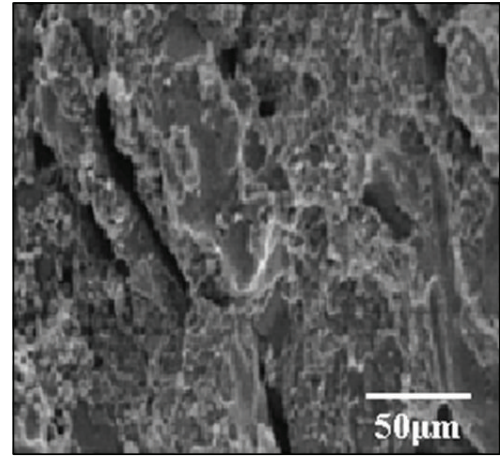

(c) Internal pores

FIGURE 1: Porous ceramic matrix specimen and its interpenetrating microstructure (SEM).

18.5 vol. $\%$ TiC powder together with 7.4 vol. $\%$ complex poreforming agent was milled for $2 \mathrm{~h}$ and then was coldcompressed into a mold at $600 \mathrm{MPa}$ and was sintered at about $1230^{\circ} \mathrm{C}$ in a vacuum furnace [8]. The specimen of the porous matrix and its microstructure are shown in Figure 1.

2.2. Wetting Experiments. A specimen of the ceramic matrix with diameter of $58 \mathrm{~mm}$ and thickness of $8 \mathrm{~mm}$ dealing with ultrasonic cleanness is used as a substrate. Then a small molten alloy block with different proportion of soft metals $\mathrm{Ag}, \mathrm{Cu}, \mathrm{Sn}$, and $\mathrm{Pb}$ is put on the surface of the specimen. After the alloy block was melted again in a vacuum high frequency induction furnace at $700^{\circ} \mathrm{C}$ for 30 minutes and cooled down, the wetting angle between the alloy and the ceramic matrix was measured.

2.3. Infiltration Experiments. To fabricate the inward gradient lubricating layer, the porous cermet, which was soaked in the $\mathrm{B}_{2} \mathrm{O}_{3}-\mathrm{KF}$ infiltration agent solution, and the lubricating alloy were put into a graphite crucible and then were rapidly heated to $700^{\circ} \mathrm{C}$ in a vacuum high frequency induction furnace. After the lubricants completely melted, the pressure of the furnace was raised to $0.3 \mathrm{MPa}$ by filling nitrogen. Holding the temperature and pressure for $30 \mathrm{mins}$, the composite was formed.

2.4. Friction Experiments. A test rig was developed for purpose of hot wear up to $600^{\circ} \mathrm{C}$. The experiment was carried out in the test rig (as shown Figure 2). The pin (4) and disc (5) specimens are placed at the center of a wire-wound tube furnace (3) temperature range of which can be changed from the room to $800^{\circ} \mathrm{C}$ by a heating instrument (2). The pin and disc are mounted in holders at the end of stainless sinter tube (1) filled with insulating ceramic fiber. The disc specimens have the shape of washers and are secured to their holder (6) by a bolt through their central hole. The friction force and dynamic loading force are measured directly by force sensors (7) and (8), respectively. Based on measured statistics, frictional coefficient can be calculated and printed out in real time by using a microprocessor controlled data acquisition system.

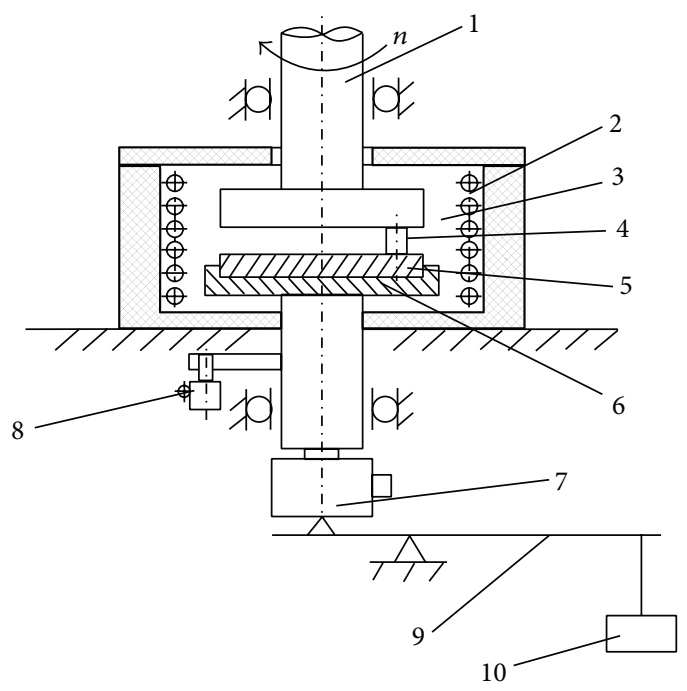

FIGURE 2: Schematic diagram of test rig.

The pins of the composite infiltrated with different lubricating alloy were tested and an alumina $\left(\mathrm{Al}_{2} \mathrm{O}_{3}\right)$ ceramic disc was used as counter face of these pins. The pins, $15 \mathrm{~mm}$ long, of $12 \mathrm{~mm}$ diameter, were rounded to hemispherical shape with diameter of $8 \mathrm{~mm}$ at one end. The disc was $58 \mathrm{~mm}$ diameter and $8 \mathrm{~mm}$ thick with an average hardness of $\mathrm{HV}$ 19.42 GPa (digital microhardness tester HVS-1000, 5 times) and a final surface roughness of $0.32 \mu \mathrm{m}$ on the counter surface. The friction tests were conducted at $600^{\circ} \mathrm{C}$ with a sliding velocity of $0.2 \mathrm{~m} / \mathrm{s}$ and a load of $50 \mathrm{~N}$.

A scanning electron microscope (SEM, HITACHI X650) equipped with an energy dispersive spectroscope (EDS, Kevex Super Quantum) was used to observe the wear surfaces of the pin and disc and the cross section of the self-lubrication layer to clarify the lubrication mechanisms.

\section{Results and Discussion}

For the purpose of obtaining an excellent tribological inward gradient lubrication layer, a series of research have been done, 


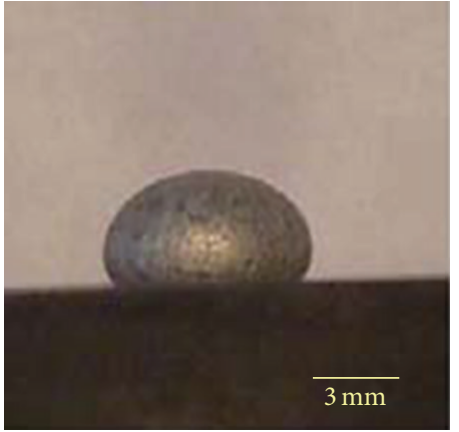

(a) $\mathrm{N}_{2}$

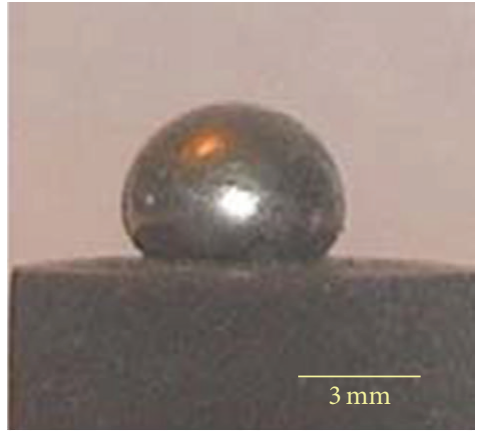

(b) $\mathrm{H}_{2}$

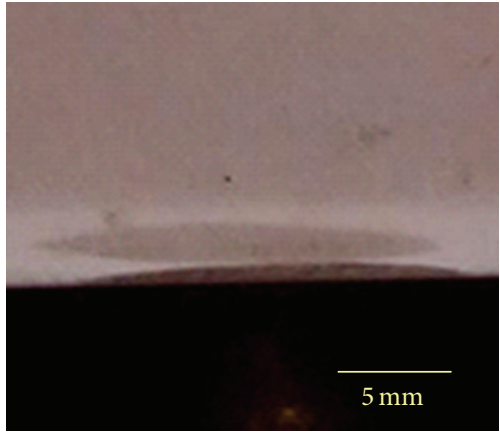

(c) $\mathrm{B}_{2} \mathrm{O}_{3}-\mathrm{KF}$ infiltration agent

FIGURE 3: Wetting angle of the soft alloys on the matrix in different environments.

mainly on the design of wetting property between the soft alloys and the ceramic composite and lubricating design of the soft alloys.

3.1. Design of Infiltration Agent. When the ceramic matrix containing $\mathrm{Cr}, \mathrm{Mo}, \mathrm{W}$, and Ti was exposed to air at elevated temperature, these elements can easily be oxidized forming an oxide film on the ceramic. The oxide film will deteriorate the wetting property of the molten soft alloy on the matrix surface. To solve the problem, two gases and infiltration agents were used in the design.

Figures 3(a), 3(b), and 3(c) show, respectively, the wetting test results of molten $\mathrm{Pb} 30 \mathrm{Sn} 20 \mathrm{Ag}$ on the ceramic matrix surface in $\mathrm{N}_{2}, \mathrm{H}_{2}$, and $\mathrm{B}_{2} \mathrm{O}_{3}-\mathrm{KF}$ agent. It is observed that the alloy has poor wetting property on the ceramic matrix surface in $\mathrm{N}_{2}$ (as shown in Figure $3(\mathrm{a})$ ) and $\mathrm{H}_{2}$ (as shown in Figure $3(\mathrm{~b})$ ) at $550^{\circ} \mathrm{C}$, but when the $\mathrm{B}_{2} \mathrm{O}_{3}-\mathrm{KF}$ agent is used in the experiment, the wetting property is markedly improved (as shown in Figure 3(c)).

Obviously, the addition of infiltration agent in the preparation process of the gradient lubrication layer effectively optimizes the wetting property of the lubricants on the matrix, so that the soft alloys can easily be infiltrated into the micropores of the ceramic matrix [9].

3.2. Wetting Design of the Soft Alloys. The melting points of soft alloys such as $\mathrm{Ag}$ and $\mathrm{Pb}$ are lower. When they are used in inward gradient layer, the infiltrating temperature should be much lower than the phase-transition temperature of the matrix, so that the strength of the ceramic matrix does not decrease in the infiltration process. On the other hand, oxides of certain soft alloys and their metal salts reacting with $\mathrm{W}$ and $\mathrm{V}$ also have excellent high temperature properties. Thus, when they are used to infiltrate into the micropores of the ceramic matrix, the inward gradient layer could have excellent high temperature lubricating properties.

However, the wetting design of the soft alloys is complicated. Some of them such as $\mathrm{Pb}$ and $\mathrm{Ag}$ have poor wetting property and solubility with $\mathrm{Fe}$, which is the major component of the matrix material, and others have better reactivity with $\mathrm{Fe}$ such as $\mathrm{Sn}[10,11]$. Therefore, it is necessary to design the soft alloys based on phase diagrams theory to improve the wetting property when they are infiltrated into the matrix materials. In the research, the design of the soft alloys component is based on phase diagrams of $\mathrm{Fe}-\mathrm{Pb}, \mathrm{Fe}-\mathrm{Ag}$, and F-Sn and lots of experiments. For the purpose of making the Sn element effectively improve the wetting ability of the soft alloys and $\mathrm{Fe}$, and limiting its high $\mathrm{SnO}_{2}$ resulting from high temperature $\left(\mathrm{SnO}_{2}\right.$ has a poor lubricating properties), the content of Sn element is always controlled lower than $30 \mathrm{wt} \%$. On the other hand, $\mathrm{Cu}$ is added to improve the wetting property of the soft alloys due to its high mutual solubility with Fe. Thus, several main designs are considered in the research: only $\mathrm{Pb}, \mathrm{Pb} 30 \mathrm{Ag}$, $\mathrm{Pb} 30 \mathrm{Sn} 20 \mathrm{Ag}$, and $\mathrm{Pb} 28 \mathrm{Sn} 19 \mathrm{Ag} 6 \mathrm{Cu}$. Their wetting properties with the ceramic matrix tested at $550^{\circ} \mathrm{C}$ are as shown in Figure 3. The spreading appearance of the soft alloys designed in Figure 3 shows that $\mathrm{Sn}$ and $\mathrm{Cu}$ can greatly improve wetting ability of the soft alloys with the ceramic matrix and the design of the $\mathrm{Pb} 28 \mathrm{Sn} 19 \mathrm{Ag} 6 \mathrm{Cu}$ presents an excellent wetting property of which the wetting angle is only about $5^{\circ}$. Based on the discussion above, a series of combinations of the soft alloys, the wetting angle measurements and lubricating experiments of them have been done with the results as shown in Figure 4.

3.3. Structural Characteristics of the Lubricating Layer. Figure 5(a) is the cross section of the inward gradient lubricating layer. It reflects the structural characteristics of the layer. The white points in the section indicate the soft alloy phase and the gray area represents the matrix phase of the ceramic composite. Obviously, an inward gradient lubrication layer is formed when the soft alloys are infiltrated into the porous matrix. As a typical example, the distribution of element Sn of soft alloys in the layer is shown in Figure 5(b).

This indicates that the lubricating elements formed an inward gradient distribution in the material and the composition design of the soft alloys is very important in controlling the thickness of the gradient lubricant layer. Therefore, it is necessary to design the thickness of the layer or control the diffusing rate of the soft alloys so that there are enough elements of soft alloys for consumption during the operating life of the frictional pairs. Fortunately, the work has been done in another paper through controlling the composition 


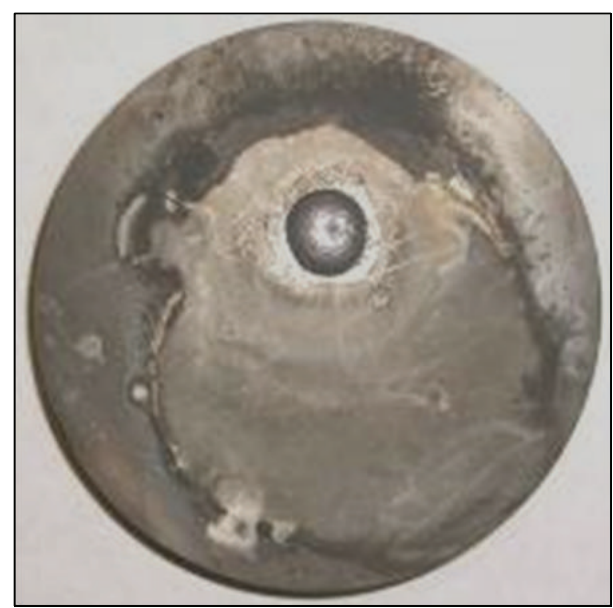

$\mathrm{Pb}$

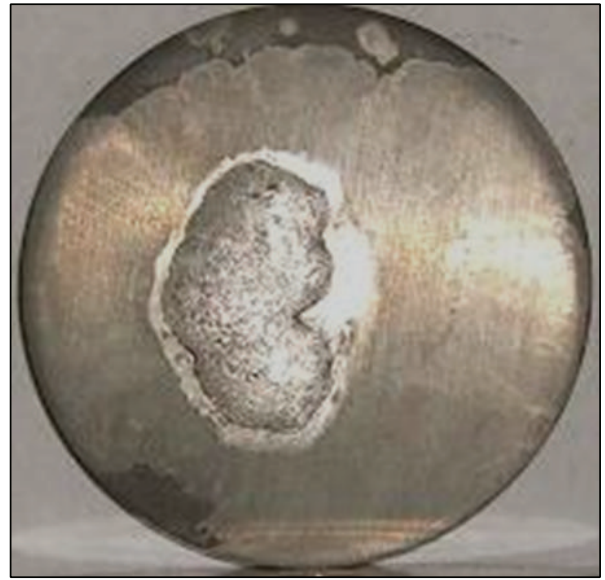

$\mathrm{Pb} 30 \mathrm{Sn} 20 \mathrm{Ag}$

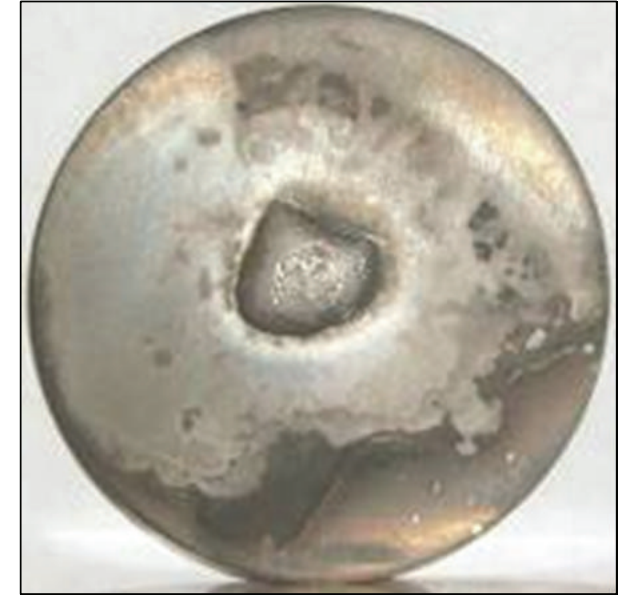

$\mathrm{Pb} 30 \mathrm{Ag}$

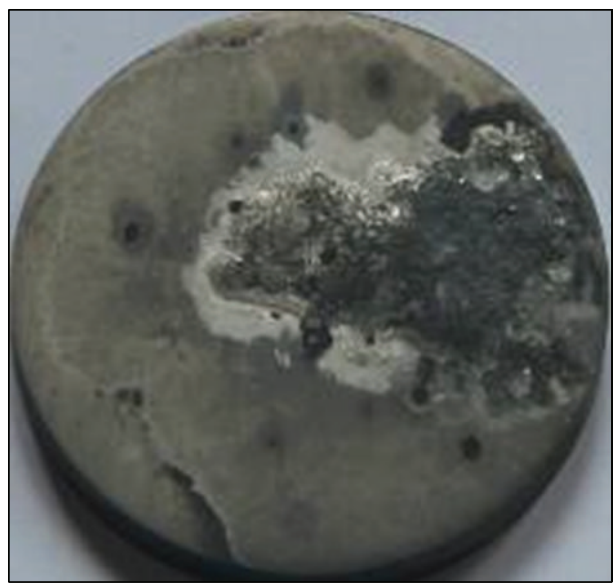

$\mathrm{Pb} 28 \mathrm{Sn} 19 \mathrm{Ag} 6 \mathrm{Cu}$

FIGURE 4: Wetting ability of the soft alloys with different compositions on the ceramic composite surface $(\phi 58)$.

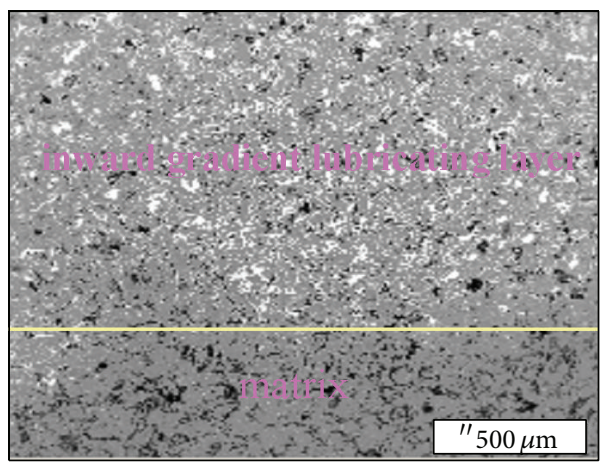

(a) Section photography

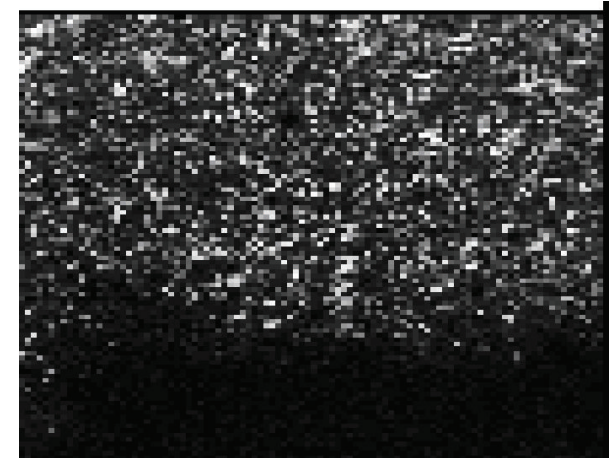

(b) Distribution of $\mathrm{Sn}$

FIGURE 5: Section photography of the gradient layer and the distribution of $S n$ in depth direction.

of soft alloys and their infiltrating parameters as well as predicting their covering rate of lubricating film on the ceramic composite worn surface at elevated temperature [12].

3.4. Lubrication Mechanism of the Composite. Figure 6 shows the friction curve of the ceramic composite with inward gradient layer at $600^{\circ} \mathrm{C}$. The curves (A-D) in Figure 6 present the friction behaviors and time of the composites infiltrated with Pb28Sn19Ag6Cu, Pb30Sn20Ag, Pb20Sn20Ag10Sb, and Pb13Au20Cu15Sn. Obviously, the ceramic composite with $\mathrm{Pb} 28$ Sn19Ag6Cu layer has a better lubrication performance of which the friction coefficient is lower than 0.3. Comparing 


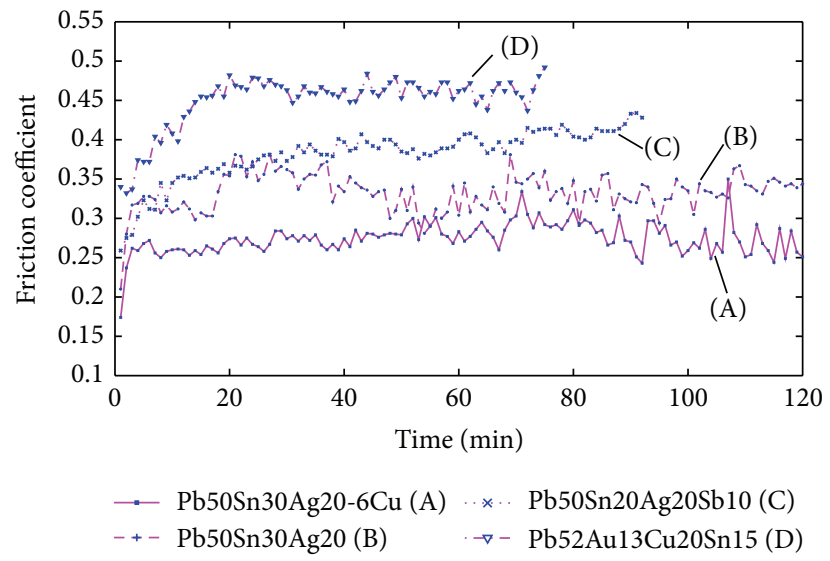

FIGURE 6: Friction coefficients of ceramic composite with gradient layer infiltrated with different soft alloys on $\mathrm{A}_{2} \mathrm{O}_{3}$ disk.

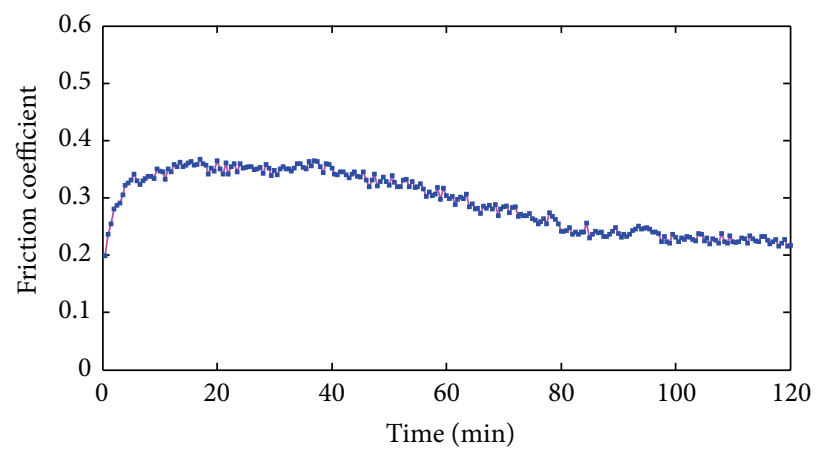

Figure 7: Friction coefficient curve of the gradient layer infiltrated with Pb28Sn19Ag6Cu sliding against $\mathrm{Al}_{2} \mathrm{O}_{3}$.

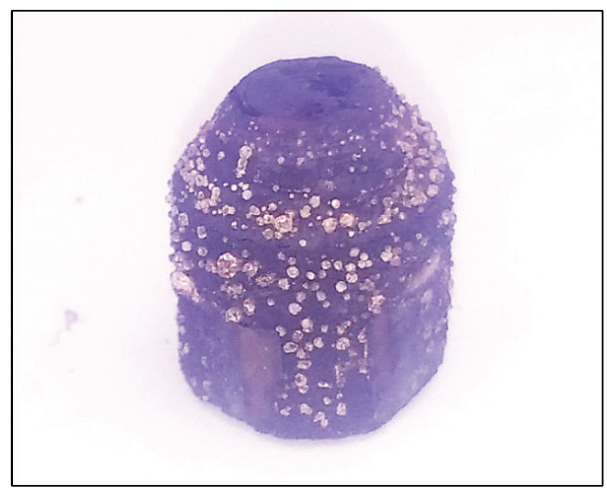

(a) Specimen after friction test

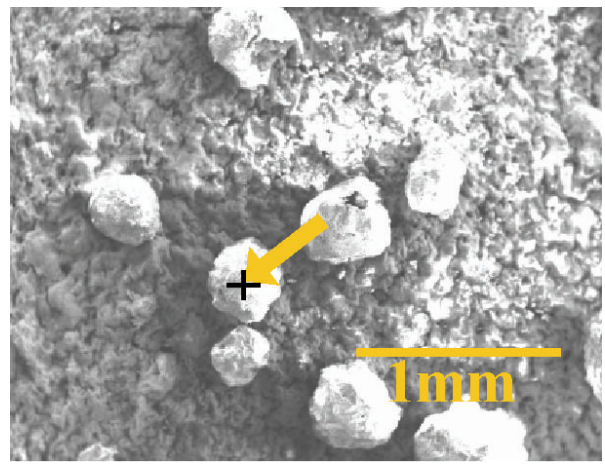

(c) Exudative morphology of the lubricant

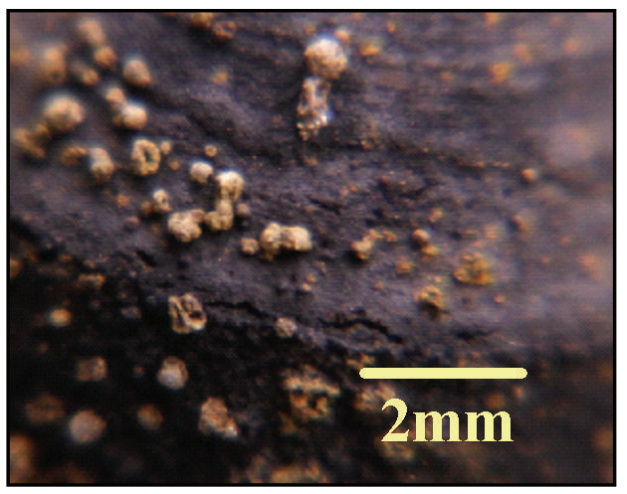

(b) Local surface of the specimen

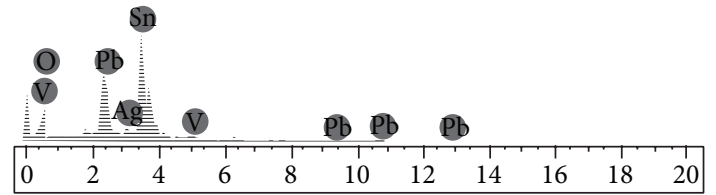

(d) Composition of the exudation

FIGURE 8: The diffusing process of the soft alloys from the inward gradient layer. 


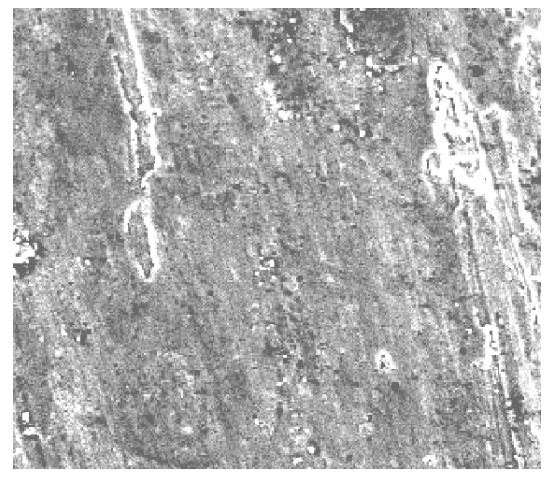

(a) Friction surface of the pin specimen

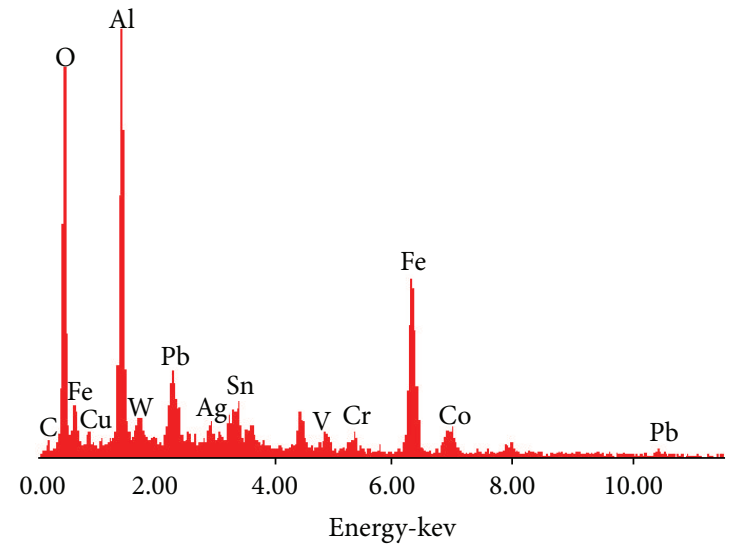

(b) The composition of the film on the disc

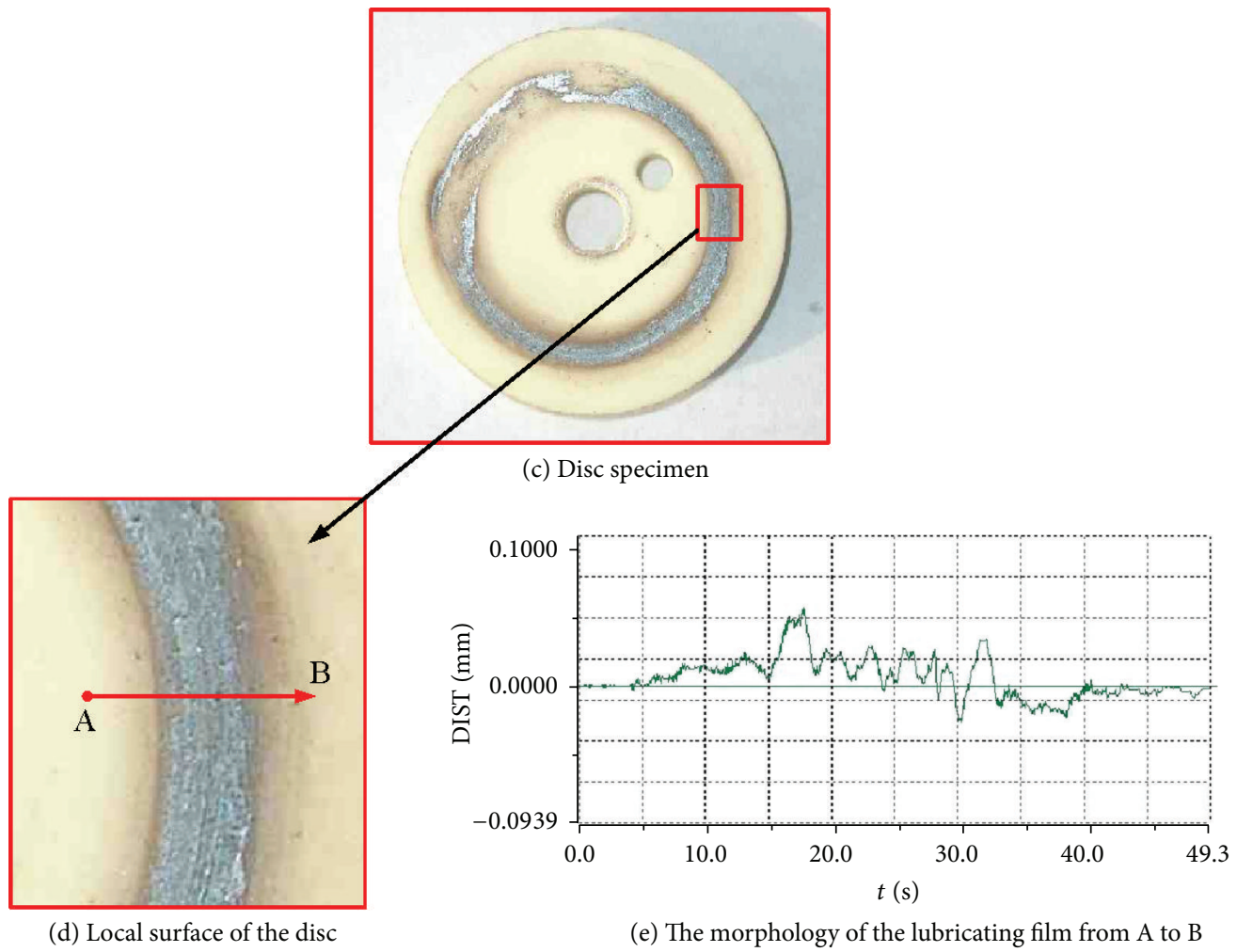

FIGURE 9: Lubricating film on the friction surface.

Figures 4 and 6, it is evident that the excellent wetting and mutual solubility of $\mathrm{Pb} 28 \mathrm{Sn} 19 \mathrm{Ag} 6 \mathrm{Cu}$ with matrix material plays an important role in formation of the lubricating film and its spreading out on the frictional surface.

In order to investigate the lubricating mechanism, the typical friction curve of ceramic composite with $\mathrm{Pb} 28$ Sn19Ag6Cu sliding against $\mathrm{Al}_{2} \mathrm{O}_{3}$ disc at $600^{\circ} \mathrm{C}$ is presented in Figure 7. In the beginning stage of the friction process, the friction coefficient is very low due to the fact that elements of soft alloys in the layer are drove out to the worn surface at high temperature. In fact, the frictional couple is actually in quasi-liquid lubrication in the case. Then, as the elements spread out but not to the extent that is enough to form a perfect lubricating film on the frictional surface, the friction coefficient increases over time. With more and more lubricant coming out in the sliding process, a perfect lubricating film is formed on the worn surface and the friction coefficient decreases and keeps on a stable value about 0.2 .

Figures $8(\mathrm{a}), 8(\mathrm{~b})$, and $8(\mathrm{c})$ show the diffusing process of the soft alloys from the ceramic composite to the inward gradient layer at high temperature friction test. It can be observed that the beads shape particles sweat out to the worn surface from the pores of the gradient layer. The major components of the particle include $\mathrm{Ag}, \mathrm{Sn}$, and $\mathrm{Pb}$. Obviously, these soft alloy elements are driven out to the friction surface by the heat expend factor and frictionalthermal stress at the high temperature sliding condition. Thus 
the diffusing mechanism provided excellent lubrication for fictional surface [13].

Figure 9 is a typical example of friction of the ceramic composite with inward gradient layer on the $\mathrm{Al}_{2} \mathrm{O}_{3}$ disc. In the experiment, the soft alloys formed a perfect lubricating film on the frictional surface (as shown in Figure 9(a)) and elements of the soft alloys in the layer such as $\mathrm{Ag}, \mathrm{Cu}, \mathrm{Sn}$, and $\mathrm{Pb}$ are present in the film (as shown in Figure 9(b)). It is evident that the soft alloys have melted at high temperature friction and mixed together to form a lubricating film because of their low melt points.

Figures 9(c), 9(d), and 9(e) show the transferring lubrication film forming on the disk worn surface. The thickness (about $20 \mu \mathrm{m}$ ) of the film is measured by coordinate measuring instrument with the results shown in Figure 9(d). It is obvious that the film has a strong adhesive force on the disk surface and an excellent anti-high temperature property. Obviously, the formation of lubrication film on the worn surface both of the composite and the disc gives the material an excellent lubricating property at elevated temperature.

\section{Conclusions}

The conclusions were as follows:

(1) By using $\mathrm{B}_{2} \mathrm{O}_{3}-\mathrm{KF}$ infiltration agent and adding $\mathrm{Sn}$ and $\mathrm{Cu}$, the wetting property of the molten lubricants on the ceramic matrix is greatly improved. For example, the wetting angle of the molten Pb28Sn19Ag6Cu on the matrix composite decreased to about $5^{\circ}$.

(2) Based on the research above, a novel inward gradient lubricating layer with $\mathrm{Pb} 28 \mathrm{Sn} 19 \mathrm{Ag} 6 \mathrm{Cu}$ is made which has an excellent lubricating property at $600^{\circ} \mathrm{C}$. The friction coefficient of the ceramic composite is about 0.2 at $600^{\circ} \mathrm{C}$.

(3) The lubrication mechanism of the composite is investigated by using SEM and EDX techniques in the research. In the high temperature sliding process, the lubricants in the lubricating layer diffusing out under the thermal and contact stress and forming lubricating film on the worn surface both of the composite and disc are the key contribution to the excellent high temperature lubricating performance of the composite.

\section{Competing Interests}

The authors declare that they have no competing interests.

\section{Acknowledgments}

The authors would like to thank National Natural Science Foundation of China for financial support (ID 51205297).

\section{References}

[1] L. Du, C. Huang, W. Zhang, T. Li, and W. Liu, "Preparation and wear performance of $\mathrm{NiCr} / \mathrm{Cr}_{3} \mathrm{C}_{2}-\mathrm{NiCr} / \mathrm{hBN}$ plasma sprayed composite coating," Surface and Coatings Technology, vol. 205, no. 12 , pp. 3722-3728, 2011.

[2] M. Antonov, I. Hussainova, F. Sergejev, P. Kulu, and A. Gregor, "Assessment of gradient and nanogradient PVD coatings behaviour under erosive, abrasive and impact wear conditions," Wear, vol. 267, no. 5-8, pp. 898-906, 2009.

[3] M. Y. Niu, Q. L. Bi, J. Yang, and W. Liu, “Tribological performances of $\mathrm{Ni}_{3} \mathrm{Si} / \mathrm{Cr}_{7} \mathrm{C}_{3}$ composite coatings under water and acid environments," Tribology International, vol. 48, pp. 216225, 2012.

[4] S. M. Aouadi, D. P. Singh, D. S. Stone et al., "Adaptive VN/Ag nanocomposite coatings with lubricious behavior from 25 to $1000^{\circ}$ C," Acta Materialia, vol. 58, no. 16, pp. 5326-5331, 2010.

[5] Z.-Y. Piao, B.-S. Xu, H.-D. Wang, and C.-H. Pu, "Experimental investigation of influence of thickness on contact fatigue lifetime of sprayed coatings," Tribology, vol. 30, no. 5, pp. 448-452, 2010 (Chinese).

[6] Y. J. Wang and Z. M. Liu, "Properties and manufacture of ceramic sinter with sweat-gland pore-structure," Chinese Journal of Mechanical Engineering, vol. 42, no. 2, pp. 27-32, 2006.

[7] Z. M. Liu, "Elevated temperature diffusion self-lubricating mechanisms of a novel cermet sinter with orderly micro-pores," Wear, vol. 262, no. 5-6, pp. 600-606, 2007.

[8] Y. J. Wang and Z. M. Liu, “Tribological properties of high temperature self-lubrication metal ceramics with an interpenetrating network," Wear, vol. 265, no. 11-12, pp. 1720-1726, 2008.

[9] S. S. Yan, X. L. Li, and Z. M. Liu, "Composition design and properties of high temperature sweating compound lubricant for infiltration," Journal of WUT (Information \& Management Engineering), vol. 35, no. 6, pp. 863-866, 2013.

[10] Q. Y. Zhang and H. S. Zhuang, Brazing and Soldering Manual, China Machine Press, Beijing, China, 1999.

[11] T. B. Massalski, Binary Alloy Phase Diagrams, American Society for Metals, Metal Park, Ohio, USA, 1986.

[12] S.-S. Yan and Z.-M. Liu, "Study of the cover rate prediction model of the lubricating film of the gland self-lubricating composite at elevated temperature," Tribology, vol. 29, no. 4, pp. 341-345, 2009.

[13] Y.-B. Zhang, S.-S. Yan, and Z.-M. Liu, "Study for the heatdriving mechanism of self-lubricating covered model at elevated temperature," Journal of Wuhan University of Technology, vol. 28 , no. 6 , pp. $20-23,2006$. 

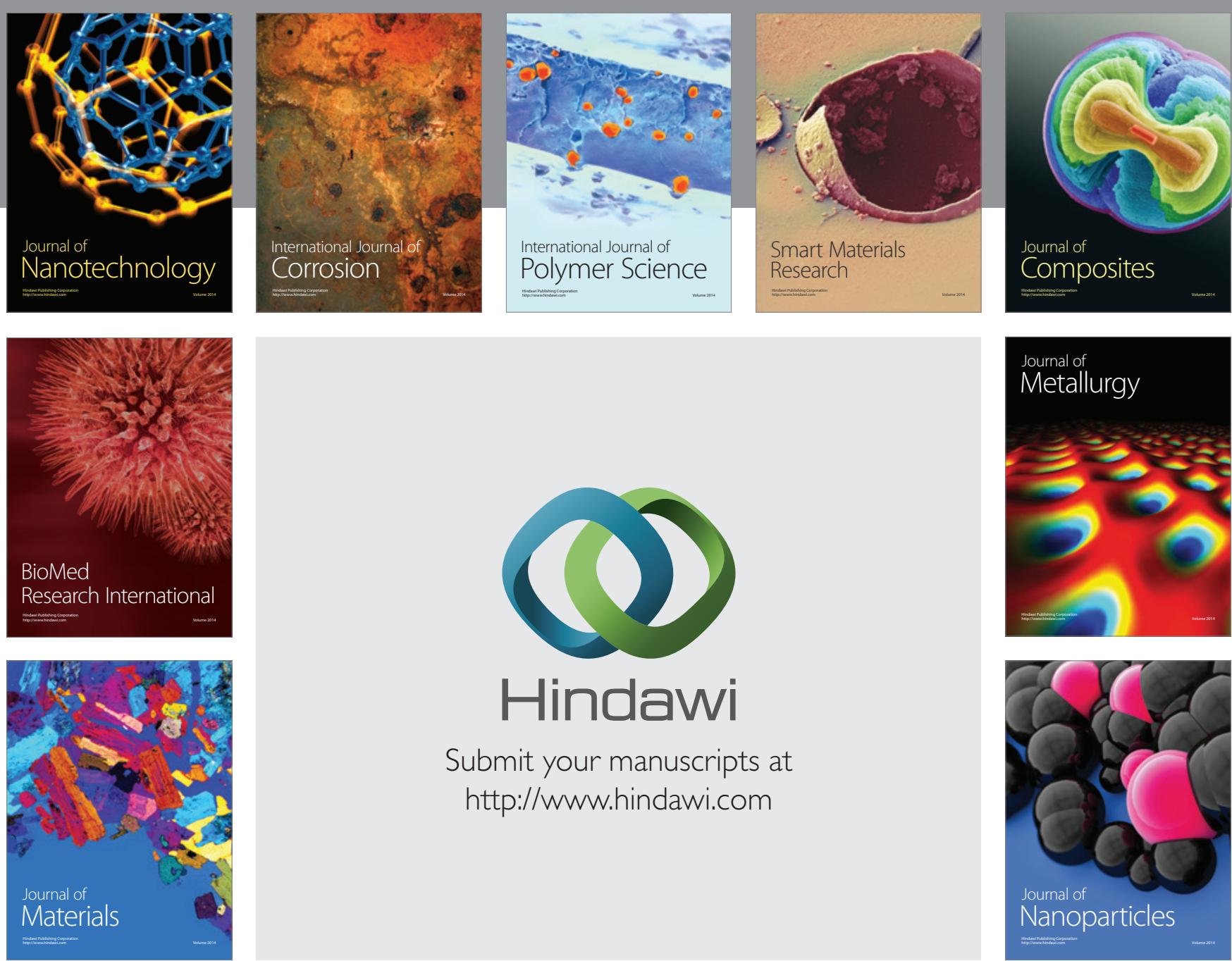

\section{Hindawi}

Submit your manuscripts at

http://www.hindawi.com

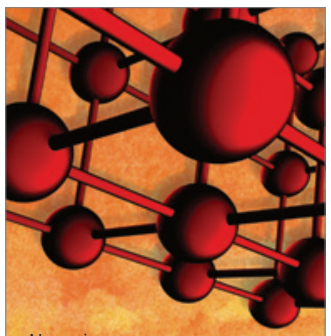

Materials Science and Engineering
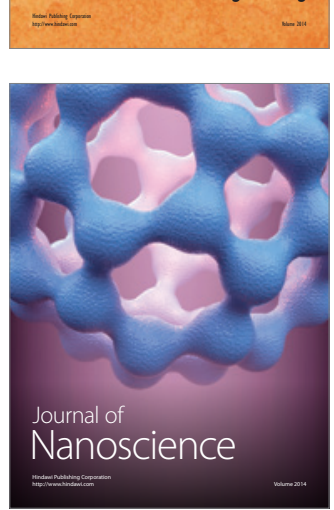
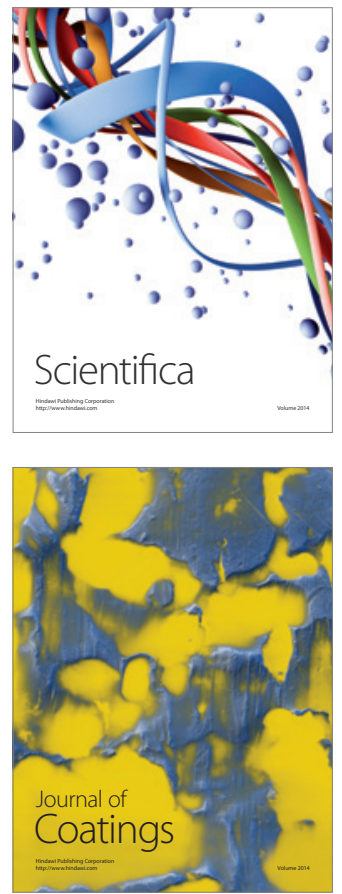
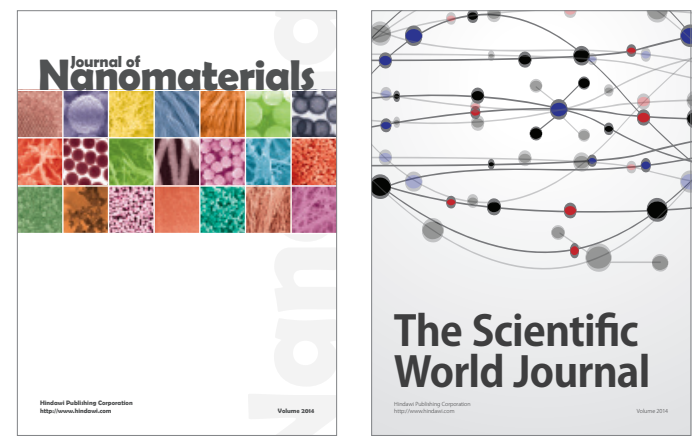

The Scientific World Journal
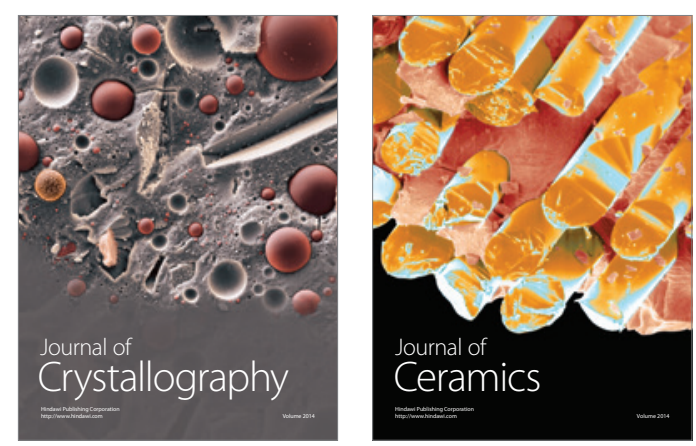
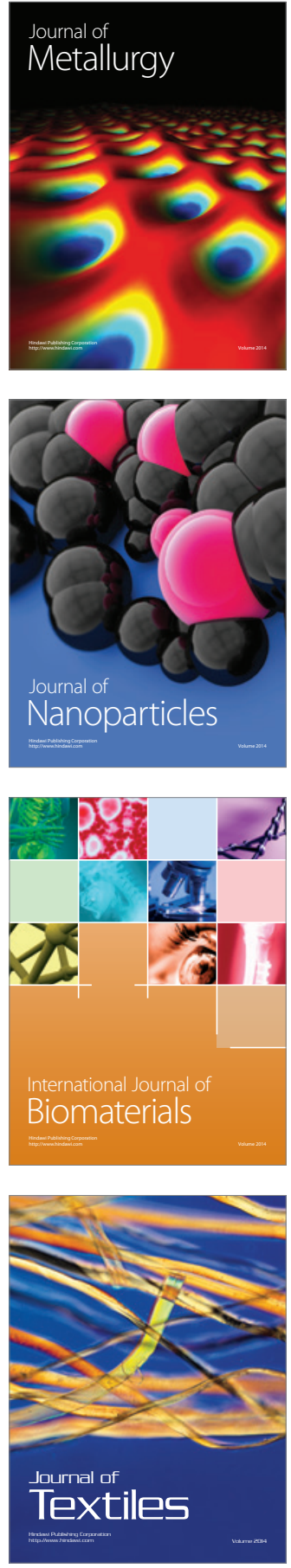